\title{
Eqüidade na legislação: um princípio do sistema de saúde brasileiro?
}

\author{
Equity in law: a Brazilian health system's principle?
}

${ }^{1}$ Departamento de Saúde Coletiva, Faculdade de Medicina de Petrópolis e Curso de Nutrição da Faculdade Arthur Sá Earp Neto, rua Machado Fagundes 326, Cascatinha, 25716-000, Petrópolis, RJ. rabelais@zaz.com.br
Abstract This article intends to delineate the definition accept in Brazilian legislation and put in question possible results of the setorial reform suggest by actual government. After a conceptual approach, the Magna Charta and Complementary Laws are analyzed. Following, assuming that the budget repass from federal to municipality government are instruments - or not - of redistribution, those mechanisms implemented by "Normas Operacionais Básicas" are analyzed, considering their capacity of promote equity. A panoramic view about reform health system reform proposes and the role of health private sector emphasizes the implications on equity. In conclusions, it's indicated that the extent of social inequalities in Brazil demand politics engaged with solidarity and equity. The Magna Charta and Complementary Laws are advanced, and the "Normas Operacionais", even so faraway to take effect the constitutional principles, shows important progresses in this direction.

Key words Equity; Health Legislation; Health Policies; Public and Private Health Sector; Health Reform
Resumo Este artigo procura delinear a concepção inerente à legislação brasileira e apontar possiveis conseqüências da reforma do setor proposta pelo atual governo. Após uma abordagem conceitual do termo eqüidade, os textos da Constituição Federal e Leis Complementares são avaliados. Em seguida, assumindo que os mecanismos de repasse de verbas do governo federal para os municipios funcionam como instrumentos de redistribuição - ou nãode recursos, são analisados aqueles implementados pelas Normas Operacionais Básicas, considerando sua capacidade de promoção de eqüidade. Uma visão panorâmica das propostas de reforma do sistema de saúde atualmente em debate e do papel desempenhado pelo setor privado de assistência é proporcionada, procurando-se enfatizar suas implicações sobre a eqüidade. À guisa de conclusão, resgata-se que as profundas desigualdades sociais existentes no Brasil exigem politicas pautadas em princípios de solidariedade e eqüidade. Neste sentido, a Constituição e Leis Orgânicas são avançadas e a normatização atual, embora ainda distante de concretizar os ditames constitucionais, apresenta progressos nesta direção.

Palavras-chave Eqüidade; Legislação de Saúde; Políticas de Saúde; Sistema Público e Privado de Saúde; Reforma do Setor Saúde 


\section{Introdução}

A eqüidade é um dos princípios fundamentais norteadores do Sistema Único de Saúde (SUS) no Brasil. Na legislação fala-se em "igualdade de assistência” (item VII, art. 7o da lei 8.080), como sinônimo de eqüidade. No entanto, a conformação de um sistema de saúde equânime pode se modificar muito, dependendo da definição adotada para o termo. O grau de eqüidade de um sistema de saúde é também determinado por vários fatores; entre os mais importantes, a forma de distribuição de recursos financeiros. É necessário considerar, ainda, a proximidade - ou distância -entre a "letra da lei” e as condições reais de saúde da população. Nesse sentido, para declarar a eqüidade como um princípio norteador do SUS, é fundamental saber até que ponto a legislação e as normas que o conformam propiciam melhorias nessas condições.

Este artigo tem como objetivo delinear o conceito de eqüidade adotado na legislação do Sistema Único de Saúde - Constituição Federal e Leis Complementares - e apontar pistas para, à luz do conceito apresentado, avaliar as possíveis conseqüências da reforma do setor proposta pelo atual governo.

\section{$O$ conceito de eqüidade}

Do ponto de vista conceitual, a temática da eqüidade tem produzido um rico debate. Longe de um consenso, diferentes concepções alimentam as teorias sobre justiça social desenvolvidas pelas diversas correntes de pensamento. Embora uma discussão aprofundada não faça parte do escopo deste trabalho, é importante lembrar que as opções conceituais, inerentes aos desenhos de sistema de saúde, orientam a escolha dos critérios distributivos (para a inversão de recursos), a escolha dos indicadores utilizados para avaliar o grau de eqüidade e a interpretação dos resultados em relação à efetividade do sistema.

No que se refere ao pensamento liberal, Porto (1994) faz uma síntese dos principais conceitos existentes, considerando suas implicações para o setor saúde. Segundo a autora, atualmente, "as tendências preponderantes reconhecem como pilares principais do conceito de eqüidade a distribuição de recursos através de uma discriminação positiva em favor dos mais desfavorecidos e a diminuição das desigualdades que resultam de fatores que estão fora do controle individual” (grifo meu). Apesar desta constatação, “a aceitação, quase consensual, de princípios eqüitativos, permanece restrita exclusivamente à definição formal de um direito, sem que na realidade seja assegurado seu efetivo exercício" (Porto, 1994).

Turner (1986) diferencia quatro tipos diferentes de eqüidade: ontológica, de oportunidade, de condições e de resultados.

A eqüidade ontológica se refere à igualdade fundamental entre as pessoas. Varia das abordagens religiosas de igualdade perante Deus, passando pela abordagem marxista - para a qual a natureza do ser humano é forjada por sua "praxis" livre e transformadora, que busca um domínio cada vez maior sobre a natureza e maior comunicação, autonomia e consciência - até as perspectivas "relativistas" modernas, de que a natureza humana é específica de certas culturas e sistemas sociais.

$\mathrm{O}$ segundo tipo, diz respeito à eqüidade de oportunidade de se alcançar os objetivos almejados. Esta concepção, herança das revoluções francesa e americana, está na base da teoria social da meritocracia, sendo uma característica da doutrina política do liberalismo clássico, que considera ser possível uma mobilidade social perfeita, a partir da igualdade de oportunidades. Uma vez garantida a universalidade dos direitos fundamentais à vida, à liberdade e à propriedade, todos têm, independente de sua origem, as mesmas oportunidades de alcançar as mais altas posições individuais. Assim, de acordo com esta concepção, as posições na estrutura ocupacional da sociedade são preenchidas apenas pelo mérito pessoal, a partir da igualdade de oportunidades para o ingresso nas instituições sociais.

De maneira apropriada, Turner resgata que a igualdade de oportunidade é praticamente inseparável da noção de eqüidade de condições. Para haver, de fato, oportunidades iguais para todos os membros da sociedade, a eqüidade precisa ser observada também no "ponto de partida": apenas pessoas submetidas às mesmas condições de vida podem vir a ser consideradas "em igualdade" para competir com base em habilidades e méritos individuais. Esta é, sem dúvida, uma concepção mais completa e complexa, que possibilita a inclusão de aspectos estruturais na determinação do grau de mobilidade das diferentes classes sociais.

Finalmente, o quarto tipo é a eqüidade dos efeitos ou resultados. Nele, a legislação e ou- 
tras medidas políticas procuram compensar os efeitos das desigualdades de condições sociais. Mecanismos de discriminação positiva precisam operar em favor de grupos menos privilegiados que têm, assim, suas oportunidades aumentadas, assegurando a eqüidade nos resultados.

A concepção ontológica trata de um debate mais inserido no campo dos sistemas morais e religiosos. No que se refere ao campo sanitário, os significados mais comuns atribuídos à eqüidade são variantes das expressões "igualdade de acesso" e "tratamentos iguais para mesmas necessidades". Estes princípios, que em geral ocupam lugar de destaque nos propósitos das políticas de saúde, coincidem com a definição adotada por Turner de "eqüidade de oportunidades". A concepção que decorre a partir desta leitura é a de que a cobertura universal dos serviços e a não discriminação de acesso aos recursos de diagnóstico e tratamento caracterizam um sistema de saúde eqüitativo. Os dois últimos tipos de eqüidade propostos por Turner são desconsiderados.

Le Grand (1988) chama a atenção para a quantidade e complexidade de questões envolvidas na aplicação, no sistema sanitário, do conceito de eqüidade, mais próximo da concepção de justiça do que de igualdade. Entre os problemas levantados por ele está o de que os significados comumente aceitos para eqüidade ignoram a distribuição desigual na população das próprias necessidades de saúde entendidas como o tipo de patologia apresentada, sua gravidade e a quantidade e sofisticação dos recursos necessários ao seu tratamento. Os grupos sociais menos privilegiados respondem a determinadas patologias de forma menos competente, exigindo, muitas vezes, cuidados mais intensivos. De fato, um exemplo disto é dado pela clássica relação existente entre pobreza, desnutrição e doenças infecciosas. Muitas destas doenças de evolução "benigna” em grupos sociais privilegiados, podem levar à morte crianças debilitadas pela desnutrição, eufemismo da fome.

Na impossibilidade de se falar em mecanismos de redistribuição de saúde, Le Grand afirma que as políticas e as ações devem estar voltadas para minimizar os fatores que produzem as desigualdades nos perfis de morbi-mortalidade. Inclui, entre estes, nutrição, condições de vida e trabalho e o próprio cuidado médico.

Um outro ponto a ser considerado, segundo Le Grand, é o fato de que nem todas as dife- renças em saúde são inevitáveis e inaceitáveis, dependendo da liberdade de escolha que o indivíduo tem ao submeter-se a situações de risco sanitário reconhecido. Diferenciais na distribuição de doenças decorrentes de hábitos que dependem de "escolhas pessoais", como fumar, beber em demasia ou dirigir em alta velocidade não podem ser considerados injustos. Whitehead (apud Giovanella et al., 1996) considera desnecessárias e injustas - portanto iniqüidades - aquelas diferenças determinadas por: comportamentos que podem causar danos à saúde, quando a liberdade de escolha de estilos de vida é restrita; exposição a condições de vida e trabalho estressantes e doentias; acesso inadequado a serviços públicos essenciais, entre eles os de saúde, e mobilidade social relacionada à saúde, envolvendo a tendência dos doentes descenderem na escala social.

O debate sobre eqüidade e justiça social no campo sanitário é rico e complexo. O maior aprofundamento e a elaboração de construções conceituais “operacionalizáveis" podem contribuir para minimizar as desigualdades decorrentes de iniqüidades sociais, especialmente importantes nos países menos desenvolvidos. Para avaliar as desigualdades existentes no Brasil, podemos esquematicamente considerar os eixos levados em conta no conceito de eqüidade de Turner, que melhor se aplicam à área da saúde - oportunidade, condições e resultados - e aplicá-los às grandes regiões do país.

Em relação à eqüidade de condições, ela pode ser avaliada através de alguns indicadores sociais ilustrados na tabela 1 . Percebe-se que a taxa de analfabetismo e a proporção de pobres no Norte e Nordeste são pelo menos duas vezes maiores do que no Sudeste e no Sul. Em relação ao abastecimento adequado de água e esgotamento sanitário, estas regiões são também as menos privilegiadas sendo que, no caso de cobertura de esgotamento sanitário, o abismo chega ao extremo de $70 \%$ no Sudeste contra $8 \%$ no Norte. Como seria esperado, o Índice de Desenvolvimento Humano, publicado pelo Programa das Nações Unidas para o Desenvolvimento, mostra os piores resultados nas regiões Norte e Nordeste do Brasil.

Um padrão semelhante ao exposto, só que às avessas, pode ser observado quando consideramos, na tabela 2, a distribuição de profissionais de saúde e de leitos para internação como indicadores de disponibilidade, um dos pré-requisitos para o acesso aos serviços (eqüi- 
Tabela 1

Indicadores sociais segundo regiões do Brasil.

\begin{tabular}{lccccc}
\hline Regiões & $\begin{array}{l}\text { \% população } \\
>\text { 15 anos } \\
\text { analfabeta } \\
(1991)\end{array}$ & $\begin{array}{l}\text { \% de domicílios } \\
\text { com abastecimento } \\
\text { adequado de água } \\
(1991)\end{array}$ & $\begin{array}{l}\text { \% de domicílios } \\
\text { com esgotamento } \\
\text { sanitário adequado } \\
(1991)\end{array}$ & $\begin{array}{l}\text { Proporção } \\
\text { de pobres (\%) } \\
(1990)\end{array}$ & $\begin{array}{l}\text { Índice de } \\
\text { Desenvolvimento } \\
\text { Humano (IDH) } \\
(1991)\end{array}$ \\
\hline Norte & 24,33 & 41,40 & 8,00 & $43^{\star}$ & 0,706 \\
Nordeste & 37,74 & 44,90 & 13,10 & 46 & 0,548 \\
Sudeste & 13,07 & 89,50 & 70,60 & 23 & 0,838 \\
Sul & 11,86 & 85,20 & 37,20 & 20 & 0,844 \\
Centro-oeste & 16,73 & 72,00 & 29,10 & 25 & 0,826 \\
\hline Brasil & 20,43 & 75,40 & 44,00 & 30 & 0,797 \\
\hline
\end{tabular}

*região urbana

Fontes: colunas 1, 2 e 3 - Ministério da Saúde, 1997a; colunas 4 e 5 - IPEA, 1996.

Tabela 2

Indicadores de recursos, mortalidade infantil e esperança de vida ao nascer, segundo regiões do Brasil.

\begin{tabular}{|c|c|c|c|c|c|c|}
\hline Regiões & $\begin{array}{l}\text { Médicos } \\
\text { por } 10 \text { mil } \\
\text { habitantes } \\
(1996) \\
\text { Conselho } \\
\text { Federal de } \\
\text { Medicina }\end{array}$ & $\begin{array}{l}\text { Enfermeiros } \\
\text { por } 10 \text { mil } \\
\text { habitantes } \\
(1996) \\
\text { Conselho } \\
\text { Federal de } \\
\text { Enfermagem }\end{array}$ & $\begin{array}{l}\text { Leitos } \\
\text { por mil } \\
\text { habitantes } \\
(1996) \\
\text { Fundação } \\
\text { Nacional } \\
\text { de Saúde }\end{array}$ & $\begin{array}{l}\text { Gasto em saúde } \\
\text { per capita R\$ } \\
\text { (tranferência } \\
\text { federal) (1996) } \\
\text { SIA/SIH/SUS } \\
\text { SAS/MS } 5\end{array}$ & $\begin{array}{l}\text { Taxa de } \\
\text { mortalidade } \\
\text { infantil } \\
(1997) \\
\text { IBGE - censos } \\
\text { demográficos } \\
\text { - estimativa }\end{array}$ & $\begin{array}{l}\text { Esperança } \\
\text { de vida } \\
\text { ao nascer } \\
(1997)\end{array}$ \\
\hline Norte & 6,02 & 2,81 & 2,1 & 24,92 & 36,00 & 67,8 \\
\hline Nordeste & 7,80 & 3,25 & 2,9 & 35,11 & 58,31 & 64,8 \\
\hline Sudeste & 18,13 & 5,13 & 3,5 & 47,02 & 26,08 & 69,0 \\
\hline Sul & 12,30 & 4,50 & 3,5 & 46,81 & 24,03 & 70,3 \\
\hline Centro-oeste & 12,51 & 3,76 & 3,8 & 41,01 & 27,05 & 68,7 \\
\hline Brasil & 13,04 & 4,23 & 3,2 & 41,56 & 37,39 & 67,8 \\
\hline
\end{tabular}

Fontes: colunas 1 a 4 - Ministério da Saúde, 1997b; coluna 5 - Ministério da Saúde, 2000b; coluna 6 - Ministério da Saúde 2000c.

dade de oportunidade). Os profissionais encontram-se em menor número nas regiões Norte e Nordeste e os leitos estão concentrados no Sudeste, Sul e Centro Oeste.

O montante de investimentos em saúde per capita, também ilustrado na tabela 2, evidencia que não houve qualquer esforço compensatório para redistribuição de recursos, que privilegiasse as áreas menos favorecidas. Mesmo com os indicadores de piores condições de vida, mostrados na tabela 1 , as regiões Norte e Nordeste não foram objeto de maiores gastos. Neste aspecto, devido aos critérios utilizados para o repasse de verbas federais, a região Sudeste recebeu os maiores aportes de recursos per capita $(\mathrm{R} \$ 47,02)$, praticamente o dobro do montante recebido pelo Norte ( R\$24,92).

Como indicadores de resultado, podemos considerar a esperança de vida e o perfil de mortalidade infantil, ilustrados na tabela 2. Embora estes indicadores sofram influência de vários outros fatores - inclusive dos diferenciais na qualidade dos registros -, tendem a refletir também as desigualdades sociais e de disponibilidade a serviços já expostas. A região Nordeste se destaca com o mais elevado nível de mortalidade infantil, 142\% maior do que o observado na região Sul, e com a menor esperança de vida, 12 anos menor do que a observada nessa mesma região. 


\section{O conceito de eqüidade na legislação brasileira}

No que se refere ao arcabouço jurídico-legal, o desenho do sistema de saúde brasileiro é apreendido na Constituição Federal de 1988, no capítulo sobre seguridade social, e detalhado nas Leis Orgânicas da Saúde, que tratam das condições para viabilizar o direito definido constitucionalmente:

- a lei 8.080, de 19 de setembro de 1990, que regulamenta o Sistema Único de Saúde em todos os níveis, dispõe sobre as condições para a promoção, proteção e recuperação da saúde, a organização e o funcionamento dos serviços correspondentes e dá outras providências;

- a lei 8.142, promulgada em 28 de dezembro de 1990, que dispõe sobre a participação da comunidade na gestão do SUS, define, em linhas gerais, as formas de transferências intergovernamentais de recursos financeiros na área da saúde e dá outras providências.

Essa legislação tem sido operacionalizada por meio de diversas portarias do Ministério da Saúde, particularmente as que originaram as Normas Operacionais Básicas - NOB’s - de 1991, 1993 e 1996. Segundo o ministério, as NOB's definem as estratégias e movimentos táticos que orientam a operacionalidade do Sistema Único de Saúde.

A Constituição de 1988, em seu artigo 196, define a saúde como "direito de todos e dever do Estado, garantido mediante políticas sociais e econômicas que visem à redução do risco de doenças e outros agravos e ao acesso universal igualitário para sua promoção, proteção e recuperação".

A lei 8.080, nos artigos 2o e 3 o das disposições gerais, reafirma esse direito, admite a existência dos fatores sociais determinantes e condicionantes da saúde, explicitando que os níveis de saúde expressam a organização econômica e social do país e inclui, como relacionadas com a saúde, todas as ações e medidas que interferem nestes fatores.

Assim, a legislação sanitária brasileira atual é avançada no conceito de eqüidade que incorpora, pelo menos no que se refere a dois eixos: o acesso universal e igualitário (eqüidade de oportunidade) e a ação sobre os determinantes dos níveis de saúde (eqüidade de condições). O Sistema Único de Saúde desenhado, em linhas gerais, na Constituição de 1988, nas leis 8.080 e 8.142 , abrange uma rede regionalizada e hierarquizada de saúde, consti- tuída por serviços públicos e "complementarmente" privados, descentralizada, com atendimento integral e com participação da comunidade.

Para viabilizar a constituição de uma política e um sistema de saúde que estejam de acordo com o princípio da eqüidade estabelecido na lei, a distribuição de recursos é ponto decisivo. Mecanismos de repasse de verbas do nível federal para os estaduais e municipais, com caráter redistributivo, podem operar no sentido de minimizar as desigualdades do país, tanto no referente a perfis de morbi-mortalidade, quanto à disponibilidade local de recursos para investimento em saúde.

Um conjunto de critérios para normatização desse repasse está definido no artigo 35 da lei 8.080. São eles:

- perfil demográfico

- perfil epidemiológico

- características qualitativas e quantitativas da rede de saúde

- desempenho técnico, econômico e financeiro

- nível de participação do setor saúde nos orçamentos estaduais e municipais

- previsão do plano qüinqüenal de investimento e

- ressarcimento do atendimento a serviços prestados em outras esferas de governo.

No mesmo artigo, parágrafo 1으, fica estabelecido que metade dos recursos financeiros destinados a estados e municípios será distribuída segundo o número de habitantes.

Vale chamar a atenção para a relevância dos critérios que consideram o perfil epidemiológico, ou seja, mais recursos nos locais onde é pior a situação sanitária e o perfil demográfico, entendido como um maior volume de recursos onde há concentração de população em faixas etárias menores ou mais velhas, consideradas de maior risco. São eles, especialmente o primeiro, os de maior potencial redistributivo. Os demais tendem a beneficiar os municípios com melhores graus de desenvolvimento socioeconômico.

Apesar da concepção avançada presente na Constituição e Leis Orgânicas, é nas Normas Operacionais Básicas que se pode avaliar os mecanismos implementados para viabilizar o desenho do sistema de saúde, seu caráter regressivo ou progressivo em termos de eqüidade e suas conseqüências sobre os níveis de saúde da população. No sentido de melhor compreender o alcance das NOB's, segue uma sín- 
tese dos conteúdos daquelas editadas em 1991, 1993 e 1996.

Em linhas gerais, a NOB 91 criou a figura do estado e município habilitados ao recebimento de transferências - repasse de verbas federais - e determinados estímulos financeiros. Para se tornarem habilitados, eles deveriam cumprir certos requisitos originários na legislação constitucional, como manter fundos e conselhos de saúde. Na prática, no entanto, a NOB 91 gerou poucas conseqüências, pois a não-adesão por parte dos municípios não paralisava os repasses. Ademais, os estímulos financeiros eram de pequena monta e irregulares (COSEMS-RJ, 1997).

A NOB 93 (Ministério da Saúde, 1993) definiu com mais clareza os critérios e os processos de enquadramento de estados e municípios habilitados e criou três níveis de gestão, configurando as seguintes situações possíveis:

- estados ou municípios não-habilitados, sendo que, neste caso, os últimos deveriam ser alvo de programa de capacitação implementado pelo estado (item 4.1.4) e

- estados ou municípios habilitados em gestão incipiente, parcial e semiplena.

Em relação ao financiamento, é digno de nota que essa norma operacional instituiu, pela primeira vez no SUS, o repasse automático fundo a fundo. Quanto aos níveis de gestão; na incipiente, os pagamentos são efetuados pela esfera federal diretamente às unidades hospitalares e ambulatoriais públicas ou privadas. Na parcial, o município recebe mensalmente a diferença de recursos correspondentes ao teto financeiro estabelecido e o pagamento efetuado diretamente pela esfera federal às unidades hospitalares e ambulatoriais. Já na gestão semiplena, o total de recursos financeiros para custeio, correspondente aos tetos ambulatorial e hospitalar estabelecidos, é recebido antecipadamente pelos municípios, que o administra com mais liberdade. Segundo análise do COSEMS-RJ, as gestões incipiente e parcial geraram poucas conseqüências práticas, porém, a gestão semiplena representou, para os municípios, os recebimentos dos recursos do SUS na forma de pré-pagamento por estimativa de gastos e maior autonomia na estruturação da rede.

Outro aspecto importante da NOB 93 foi a criação das Comissões Intergestores, como mecanismo de consulta e decisões entre governos, no plano nacional e regional. São elas:

\section{no âmbito nacional}

- Comissão Intergestor Tripartite (CIT) composta paritariamente por representação do Ministério da Saúde (MS), do Conselho Nacional de Secretários Estaduais de Saúde (CONASS) e do Conselho Nacional de Secretários Municipais de Saúde (CONASEMS). Sua atribuição é assistir o Ministério da Saúde na elaboração de propostas para implantação e operacionalização do SUS, submetendo-se ao poder deliberativo e fiscalizador do Conselho Nacional de Saúde (CNS), constituído conforme o decreto no 99.438/90 e responsável pela formulação de estratégias e pelo controle da execução da política nacional de saúde.

\section{no âmbito estadual}

- Comissão Intergestor Bipartite (CIB) composta, de forma paritária, por representantes da Secretaria Estadual de Saúde (SES) e do Conselho de Secretários Municipais de Saúde do Estado ou órgão equivalente, podendo operar com subcomissões regionais. A CIB é uma instância privilegiada de negociação e decisão quanto aos aspectos operacionais do SUS nos estados. Suas decisões devem ser referendadas ou aprovadas pelo respectivo Conselho Estadual de Saúde (CES), que permanece como instância responsável pela formulação de estratégias e controle da execução da política estadual de saúde, com atribuições previstas em lei estadual, observado o disposto na lei $8.142 / 90$.

Vale lembrar que, no âmbito do município, o Conselho Municipal de Saúde é o órgão responsável pela formulação de estratégias e controle da execução da política municipal, atuando como instância permanente e deliberativa, com composição e atribuições previstas em lei municipal e na lei 8.142, de 1990.

No que se refere à eqüidade, Porto (1994) afirma que o Ministério da Saúde implementou, nas Normas Operacionais de 1991 e 1993, uma sistemática para os repasses financeiros da esfera federal para os níveis estaduais e municipais, que não guarda relação com as disposições da lei 8.080. São três os problemas apontados pela autora.

1) O repasse de verbas é calcado fundamentalmente na remuneração por serviços prestados, tanto para o serviço público como para o privado contratado. Ambos são considerados vendedores de atenção à saúde e o mi- 
nistério é o comprador que remunera por produtividade. Considerando que a demanda de cada um deles é distinta em relação ao perfil epidemiológico - casos mais graves e dispendiosos são atendidos no setor público - e que, além disto, o grau de autonomia administrativa é também diferente, a autora sugere que a homogeneidade da forma de pagamento e nos valores atribuídos às atividades médico-assistenciais produzem uma desvantagem do serviço público em relação ao setor privado contratado.

2) A divisão dos municípios por níveis de descentralização está subordinada a um extenso leque de requisitos que classificam os municípios em diferentes tipos de gestão (incipiente, parcial e semiplena). Esta divisão, especialmente considerando a gestão semiplena em relação às demais, tem implicações importantes no volume de recursos a serem gerenciados pelo município. Apesar de estimular a criação de Conselhos Municipais de Saúde, favorece os municípios com maior número de habitantes e melhores níveis de desenvolvimento socioeconômico, que têm mais capacidade de responder aos requisitos definidos pelo ministério. Isto pode ser percebido na proporção de municípios habilitados pelo Ministério da Saúde em novembro de 1995. Nessa ocasião, havia 2.795 (56\%) municípios habilitados entre os 4.974 existentes. Destes, 2.131 (43\%) estavam em condição incipiente, 612 (12\%) em parcial e apenas 52 (1\%) em condição semiplena. Em outubro de 1996, o número de municípios enquadrados na semiplena havia chegado a 126 (COSEMS-RJ, 1996).

3) Os principais fluxos de recursos existentes são para o financiamento das atividades hospitalares e ambulatoriais.

Em relação ao financiamento das atividades hospitalares, o sistema é de pós-pagamento prospectivo, por procedimento, isto é, os recursos são repassados a partir de Autorizações de Internação Hospitalar (AIH) faturadas, as quais são remuneradas por procedimento, cujos valores são previamente definidos pelo nível central. Este tipo de financiamento, com base em valores médios discriminados em uma tabela de procedimentos, não pondera a quantidade de atos médicos efetuados em cada internação, nem diferencia os tipos de prestadores. Algumas das conseqüências observadas em sistemas similares de pagamento estão relacionadas com a diminuição da média de permanência por internação, o que po- de comprometer a qualidade dos serviços prestados. Tende também a ocorrer uma diferenciação no perfil epidemiológico da demanda atendida pelos setores públicos e privados, incentivando o não-atendimento pelo setor privado ou a derivação, para outras instituições, de pacientes que demandem procedimentos nos quais a relação entre o valor pago pelo SUS e o custo seja pouco vantajosa ou deficitária. Nesse sentido, é grande a chance dessa diferenciação operar com maior prejuízo para os menos privilegiados que, como mencionado, muitas vezes exigem níveis de cuidados acima da média estabelecida para o tratamento de certas patologias.

Existe também a possibilidade de repasse ao município de quantias excedentes à sua produtividade em números de AIH (Autorização para Internação Hospitalar). No entanto, esta transferência é limitada por um teto e está diretamente relacionada com o tipo de gestão do município. Somente os municípios sob gestão parcial ou semiplena e, portanto, os mais desenvolvidos, recebem este saldo, caso ele exista.

No financiamento das atividades ambulatoriais, os tetos municipais estão limitados a valores estabelecidos pelo Ministério da Saúde, com prévia consulta à Comissão Tripartite e aprovação do Conselho Nacional de Saúde. Estes valores variam para os Estados, segundo as características da população, capacidade instalada, complexidade da rede, desempenho financeiro e desempenho de auditoria estadual no ano anterior. Em 1993, por exemplo, os maiores valores foram estabelecidos para os Estados do Paraná, Minas Gerais e Rio de Janeiro, que correspondiam a mais do que o dobro do menor valor, estabelecido para os Estados do Acre, Amapá, Rondônia, Amazonas, Roraima, Pará, Maranhão, Mato Grosso e Tocantins. Para Porto, estas variações, longe de diminuírem as diferenças existentes, contribuem, no mínimo, para sua consolidação.

A NOB 96 (Ministério da Saúde, 1996), vigente atualmente, reduziu os níveis de gestão para dois, tanto nos municípios (Plena da Atenção Básica e Plena do Sistema Municipal) como para os estados (Avançada do Sistema Estadual e Plena do Sistema Estadual). O quadro 1 traz os principais aspectos que descrevem cada tipo de gestão no nível municipal.

Uma das principais novidades da NOB 96 é a Programação Pactuada e Integrada (PPI). O objetivo é que o processo de programação de atividades e tomada de decisões favoreçam a 


\section{Quadro 1}

Síntese dos principais aspectos que caracterizam as condições de gestão de municípios na NOB 93 e 96 .

\begin{tabular}{|c|c|c|c|}
\hline Tipo de gestão & Responsabilidades & Requisitos & $\begin{array}{l}\text { Implicações quanto } \\
\text { ao repasse das verbas }\end{array}$ \\
\hline $\begin{array}{l}\text { Plena da } \\
\text { atenção básica }\end{array}$ & $\begin{array}{l}\text { a) desenvolvimento de atividades } \\
\text { de coordenação, articulação, } \\
\text { negociação, planejamento, } \\
\text { acompanhamento, controle, } \\
\text { avaliação e auditoria de serviços } \\
\text { de assistência básica - contidos } \\
\text { no PAB - inclusive domiciliares } \\
\text { e comunitários, e elaboração } \\
\text { de proposta de referência } \\
\text { ambulatorial especializada } \\
\text { e hospitalar, com incorporação } \\
\text { negociada à programação } \\
\text { estadual } \\
\text { b) gerência de unidades próprias } \\
\text { e ambulatoriais do Estado ou } \\
\text { da União, salvo determinações } \\
\text { em contrário da CIB ou da CIT } \\
\text { c) autorização das internações } \\
\text { hospitalares e procedimentos } \\
\text { ambulatoriais especializados, } \\
\text { que sejam pagos por produção } \\
\text { de serviços } \\
\text { d) manutenção de cadastro } \\
\text { atualizado das unidades } \\
\text { assistenciais sob sua gestão } \\
\text { e alimentação dos bancos de } \\
\text { dados de interesse nacional } \\
\text { e estadual } \\
\text { e) execução das ações básicas } \\
\text { de vigilância sanitária, incluídas } \\
\text { no PBVS e das ações básicas de } \\
\text { epidemiologia, incluídas no } \\
\text { TFECD } \\
\text { f) avaliação do impacto } \\
\text { das ações do sistema sobre } \\
\text { as condições de saúde dos } \\
\text { munícipes e sobre o meio } \\
\text { ambiente }\end{array}$ & $\begin{array}{l}\text { a) comprovar funcionamento } \\
\text { do CMS e operação do Fundo } \\
\text { Municipal de Saúde } \\
\text { b) comprovar capacidade técnica } \\
\text { e administrativa e condições } \\
\text { materiais para o exercício de suas } \\
\text { responsabilidades e prerrogativas } \\
\text { quanto à contratação, pagamento, } \\
\text { controle e auditoria dos serviços } \\
\text { sob sua gestão } \\
\text { c) comprovar dotação } \\
\text { orçamentária do ano e dispêndio } \\
\text { realizado no ano anterior, } \\
\text { correspondente à contrapartida } \\
\text { de recursos financeiros próprios } \\
\text { d) comprovar capacidade } \\
\text { para desenvolvimento de } \\
\text { ações de vigilância sanitária } \\
\text { e epidemiológica } \\
\text { e) comprovar disponibilidade } \\
\text { de estrutura e recursos humanos } \\
\text { para supervisão e auditoria } \\
\text { da rede de unidades, dos } \\
\text { profissionais e dos serviços } \\
\text { realizados } \\
\text { f) comprometer-se a } \\
\text { participar da elaboração } \\
\text { e da implementação da PPI } \\
\text { e apresentar o Plano } \\
\text { Municipal de Saúde }\end{array}$ & $\begin{array}{l}\text { a) transferência, regular } \\
\text { e automática, dos recursos } \\
\text { correspondentes ao: } \\
\text { - Piso da Atenção Básica } \\
\text { - Piso Básico de Vigilância } \\
\text { Sanitária } \\
\text { - Ações básicas de } \\
\text { epidemiologia e de } \\
\text { controle de doenças } \\
\text { b) subordinação à gestão } \\
\text { municipal de todas as } \\
\text { unidades básicas de saúde, } \\
\text { estatais ou privadas (lucrativas } \\
\text { e filantrópicas), estabelecidas } \\
\text { no território municipal }\end{array}$ \\
\hline $\begin{array}{l}\text { Plena do sistema } \\
\text { municipal, para } \\
\text { a qual convergem } \\
\text { os enquadrados na } \\
\text { gestão semiplena }\end{array}$ & $\begin{array}{l}\text { a) desenvolvimento de atividades } \\
\text { de coordenação, articulação, } \\
\text { negociação, planejamento, } \\
\text { acompanhamento, controle, } \\
\text { avaliação e auditoria de toda } \\
\text { a rede de assistência, com } \\
\text { incorporação negociada à } \\
\text { programação estadual }\end{array}$ & $\begin{array}{l}\text { além dos que caracterizam a } \\
\text { Gestão Plena de Atenção Básica: } \\
\text { g) comprovar o funcionamento de } \\
\text { serviço estruturado de vigilância } \\
\text { sanitária, epidemiológica } \\
\text { e de controle de zoonoses } \\
\text { h) participar da PPI e apresentar } \\
\text { o Plano Municipal de Saúde }\end{array}$ & $\begin{array}{l}\text { a) transferência, regular e } \\
\text { automática, dos recursos } \\
\text { correspondentes ao TFA } \\
\text { b) normalização complementar } \\
\text { relativa ao pagamento } \\
\text { de prestadores de serviços } \\
\text { assistenciais em seus territórios, } \\
\text { tendo a tabela nacional como } \\
\text { referência mínima }\end{array}$ \\
\hline
\end{tabular}


Quadro 1 (continuação)

\begin{tabular}{|c|c|c|c|}
\hline Tipo de gestão & Responsabilidades & Requisitos & $\begin{array}{l}\text { Implicações quanto } \\
\text { ao repasse das verbas }\end{array}$ \\
\hline $\begin{array}{l}\text { Plena do sistema } \\
\text { municipal, para } \\
\text { a qual convergem } \\
\text { os enquadrados na } \\
\text { gestão semiplena }\end{array}$ & $\begin{array}{l}\text { b) gerência de unidades } \\
\text { ambulatoriais e hospitalares, } \\
\text { próprias, do Estado e da União, } \\
\text { inclusive as de referência } \\
\text { c) operação do SIH e do } \\
\text { SIA/SUS, conforme normas do } \\
\text { MS, e alimentação, junto à SES, } \\
\text { dos bancos de dados de interesse } \\
\text { nacional } \\
\text { d) administração da oferta de } \\
\text { procedimentos ambulatoriais de } \\
\text { alto custo e hospitalares de alta } \\
\text { complexidade, conforme a PPI } \\
\text { e) execução das ações básicas, de } \\
\text { média e alta complexidade em } \\
\text { vigilância sanitária }\end{array}$ & $\begin{array}{l}\text { contendo metas estabelecidas, } \\
\text { a integração e articulação do } \\
\text { município na rede estadual } \\
\text { e respectivas responsabilidades } \\
\text { na programação integrada do } \\
\text { estado, incluindo detalhamento } \\
\text { da programação de ações } \\
\text { e serviços e indicadores } \\
\text { de acompanhamento } \\
\text { i) assegurar a oferta de todo } \\
\text { o elenco de procedimentos } \\
\text { cobertos pelo PAB e de } \\
\text { serviços de apoio, diagnóstico } \\
\text { em patologia clínica e radiologia } \\
\text { básicas } \\
\text { j) comprovar a estruturação } \\
\text { do componente municipal do } \\
\text { Sistema Nacional de Auditoria }\end{array}$ & $\begin{array}{l}\text { c) transferência, regular } \\
\text { e automática, fundo a fundo, } \\
\text { dos recursos correspondentes } \\
\text { ao PBVS } \\
\text { d) remuneração por serviços } \\
\text { de vigilância sanitária de } \\
\text { média a alta complexidade } \\
\text { e remuneração pela execução } \\
\text { do PDAVS, quando assumido } \\
\text { pelo município } \\
\text { e) transferência de } \\
\text { recursos referentes às } \\
\text { ações de epidemiologia } \\
\text { e de controle de doenças } \\
\text { f) subordinação à gestão } \\
\text { municipal, do conjunto } \\
\text { de todas as unidades } \\
\text { ambulatoriais especializadas } \\
\text { e hospitalares, estatais } \\
\text { ou privadas lucrativas } \\
\text { e filantrópicas) estabelecidas } \\
\text { no território municipal }\end{array}$ \\
\hline
\end{tabular}

Fonte: adaptado de Ministério da Saúde, 1996.

integração dos três níveis do sistema de saúde. No âmbito municipal a programação é elaborada e submetida ao Conselho Municipal de Saúde. Nos âmbitos estaduais e federal, a PPI é negociada nas Comissões Intergestores (CIB e CIT) e submetida aos respectivos Conselhos de Saúde. De acordo com o item 11.1.1 da NOB 96: a PPI envolve atividades de assistência ambulatorial e hospitalar, de vigilância sanitária e de epidemiologia e controle de doenças, constituindo um instrumento essencial de reorganização do modelo de atenção e da gestão do SUS, de alocação dos recursos e de explicitação do pacto estabelecido entre as três esferas de governo. Essa programação traduz as responsabilidades de cada município com a garantia de acesso da população aos serviços de saúde, quer pela oferta existente no próprio município quer pelo encaminhamento a outros municípios, sempre por intermédio de relações entre gestores municipais mediadas pelo gestor estadual.

O financiamento da política sanitária é, como antes, baseado em transferências da União para estados e municípios e nos recur- sos oriundos do tesouro estadual e municipal em cada localidade. Como parâmetros para regular as transferências, propõe-se a combinação de critérios fundados na população e na oferta de serviços. Em qualquer nível de gestão é prevista alguma forma de transferência de recursos automática, fundo a fundo. A NOB 96 se propõe também a estabelecer regras fundamentadas no risco epidemiológico e a favorecer programas considerados estratégicos, COmo os de saúde da família e os de agentes comunitários de saúde, através de incentivos financeiros.

Para alcançar esses objetivos, foi criado um sistema complexo de mecanismos de repasse de verbas federais para os municípios, que encontra-se sintetizado no quadro 2. Entre pisos, índices e frações, são quinze formas diferentes de repasse de verbas, incluídas em um Teto Financeiro Global do Município (TFGM), composto pela soma dos Tetos Financeiros de Assistência do Município (TFAM); de Vigilância Sanitária (TFVS) e de Epidemiologia e Controle de Doenças (TFECD). São sete mecanis- 


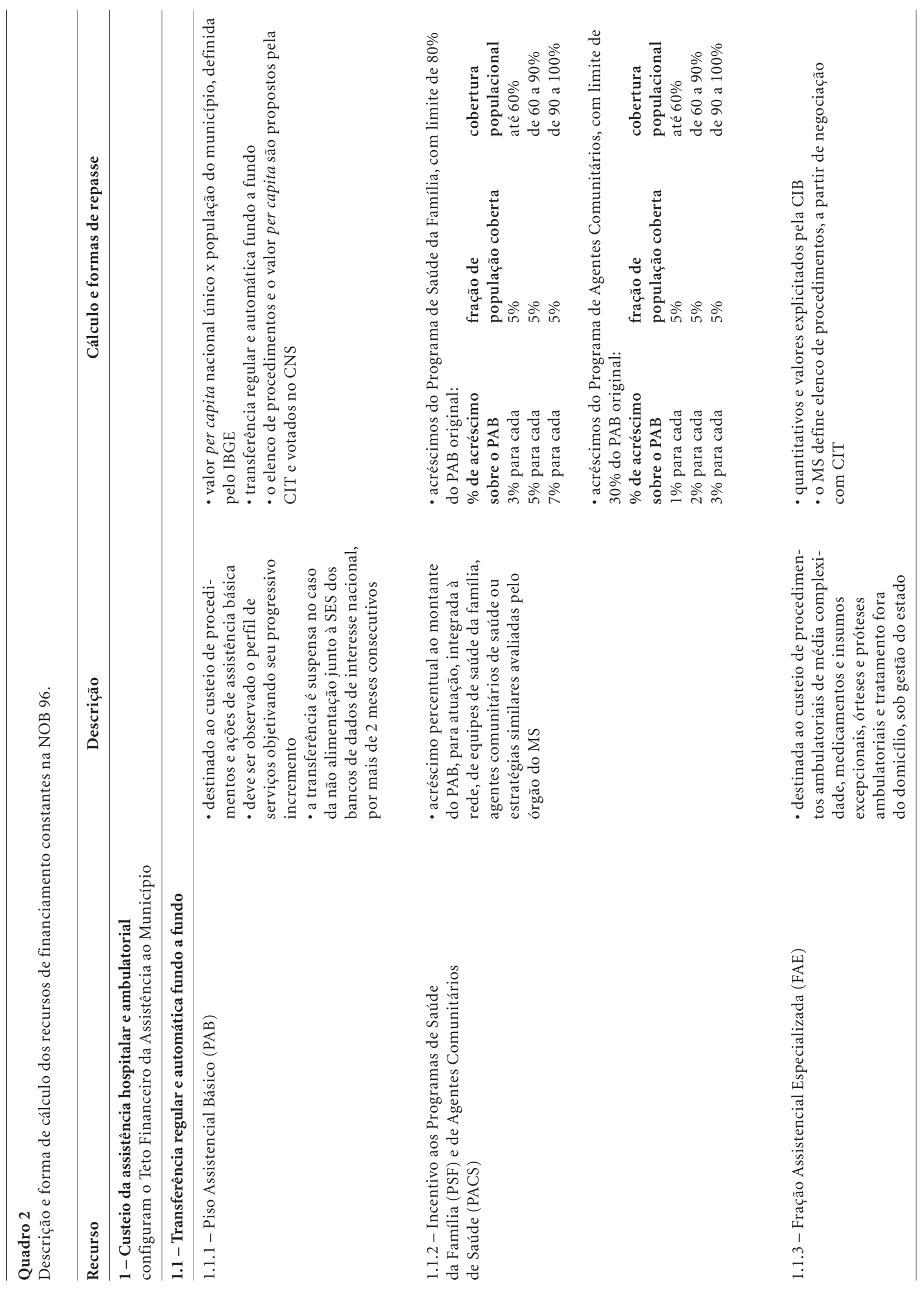




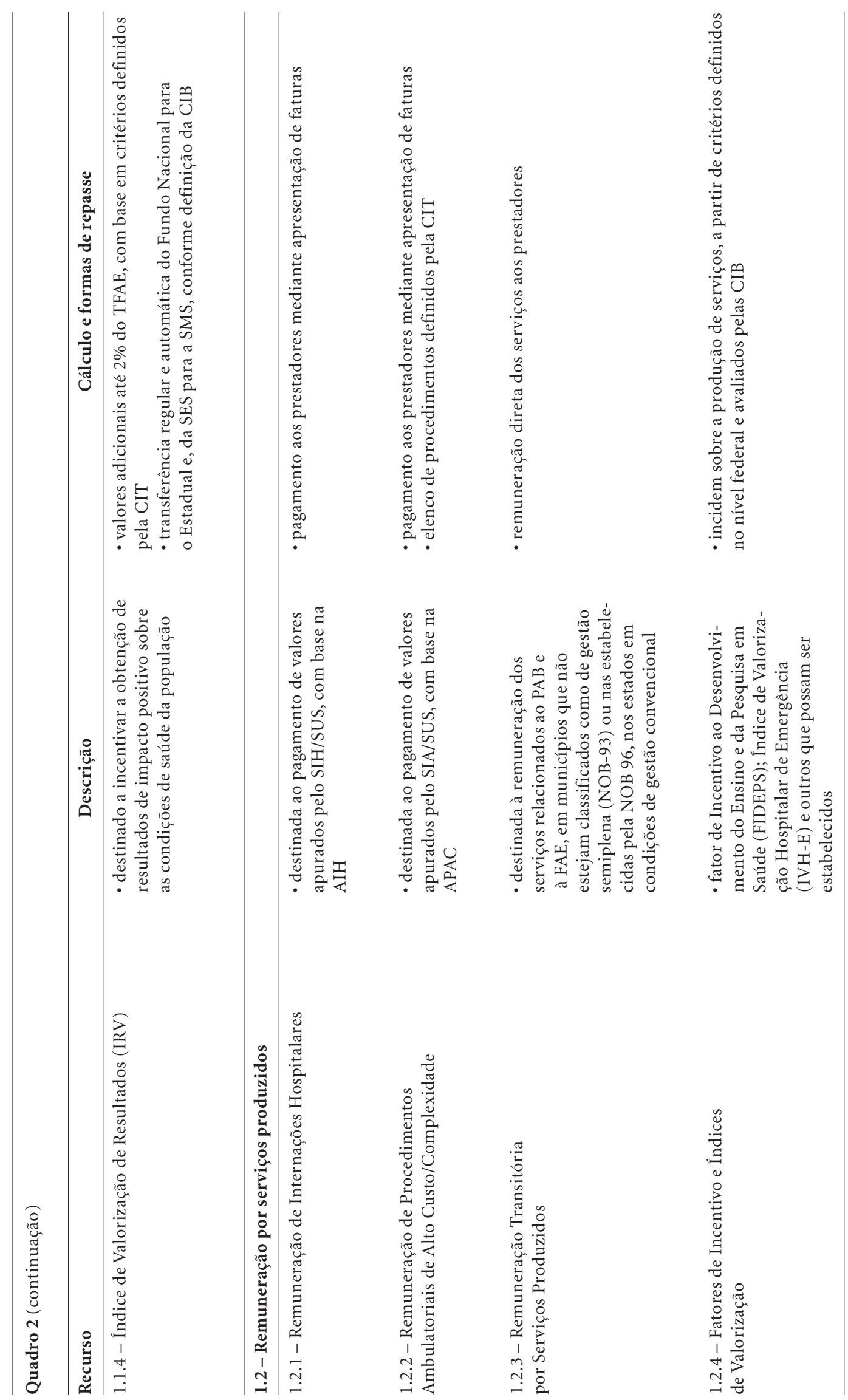




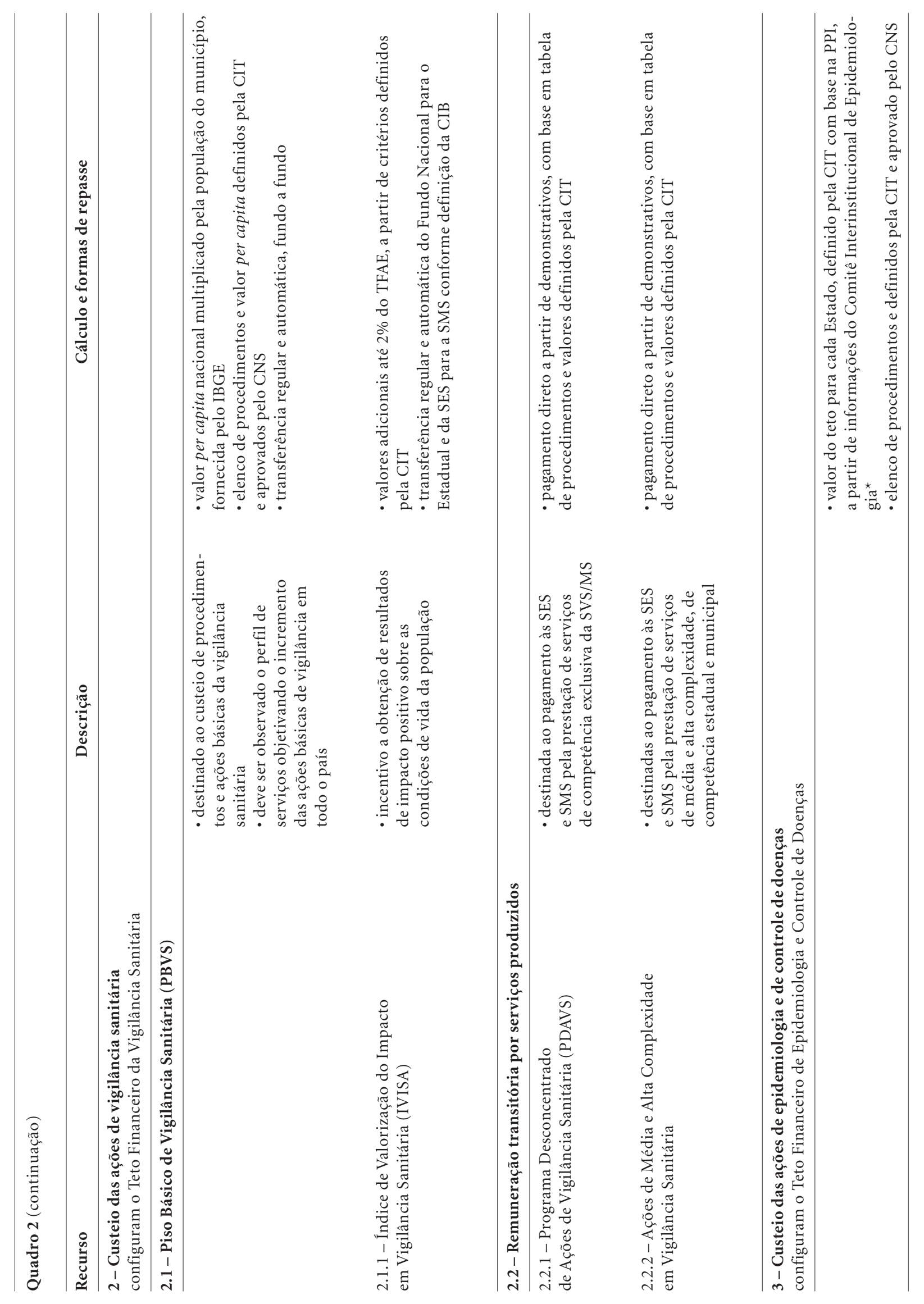




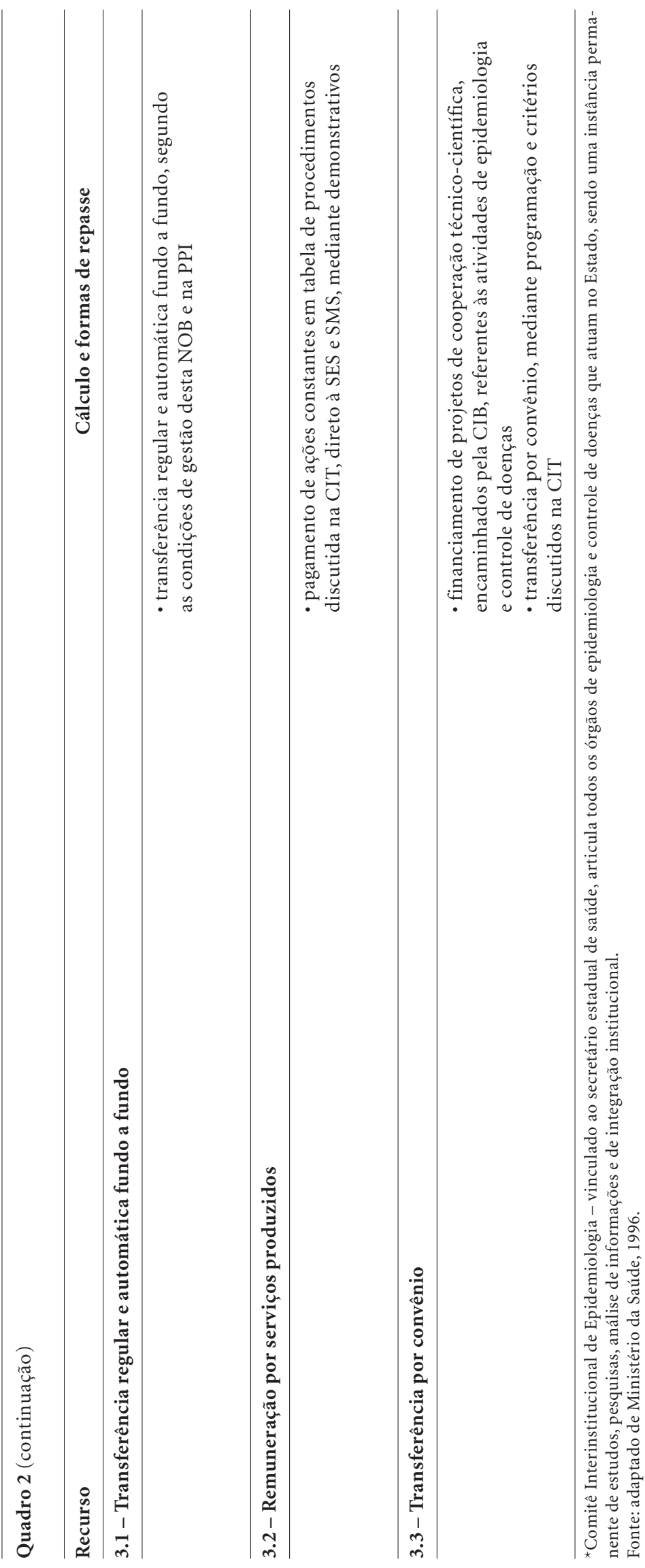


mos de repasse automático fundo a fundo, sete de remuneração por serviços produzidos e um através de convênios.

Todos os valores referentes a pisos, tetos, frações e índices, bem como suas revisões, são definidos com base na Programação Pactuada Integrada, negociados nas Comissões Intergestores (CIB e CIT), aprovados nos respectivos Conselhos de Saúde e formalizados em atos dos gestores estadual e federal.

As Comissões Intergestores têm, assim, um papel central, sendo o fórum para onde convergem as "decisões pactuadas" que, entre outras implicações, interferem diretamente na divisão dos recursos financeiros da União entre os municípios e estados. O próprio processo de habilitação passa por essas instâncias.

Quanto à eqüidade, pode-se considerar que alguns dos problemas apontados por Porto nas NOB's anteriores vêm sendo contornados na atual, embora outros permaneçam como obstáculos importantes.

A remuneração por serviços produzidos permanece como forma de pagamento das internações hospitalares e procedimentos ambulatoriais de alto custo/complexidade. A nãodiferenciação entre os tipos de prestadores continua tendendo a comprometer a qualidade da atenção e a canalizar, para o serviço público, os casos mais graves e dispendiosos, tornando a relação custo/benefício (valor investido no paciente/resposta ou recuperação do paciente) sistematicamente pior no serviço público.

Por outro lado, a possibilidade de repasse de verbas através de incentivos foi ampliada. Nesse sentido, pode-se considerar que os principais recursos com potencial redistributivo são:

- o Incentivo aos Programas de Saúde da Família e de Agentes Comunitários de Saúde partindo do pressuposto de que estes programas tenderiam a atender a uma parcela maior do que aquela que habitualmente chega à rede de assistência, pode-se considerar que o acesso aos cuidados de saúde é ampliado, potencializando o impacto sobre os índices de morbi-mortalidade. Estes incentivos podem chegar a ultrapassar o dobro dos valores estipulados para o Piso Assistencial Básico, já que trabalham com um limite de, respectivamente, $80 \%$ e $30 \%$ de acréscimo, para os programas de saúde da família e agentes comunitários;

- Índice de Valorização de Resultados - apesar de se referir a impactos positivos sobre as condições de saúde da população, os valores adicionais não podem ultrapassar $2 \%$ do $\mathrm{Pi}$ so de Atenção Básica (PAB);

- Índice de Valorização do Impacto em Vigilância Sanitária - se refere a impactos positivos sobre as condições de vida da população e também está submetido a um valor máximo, que corresponde a $2 \%$ do Teto Financeiro de Vigilância Sanitária;

- Custeio das Ações de Epidemiologia e Controle de Doenças - com potencial redistributivo, contém três formas diferentes de repasse: transferência automática fundo a fundo, remuneração por serviços produzidos e transferência por convênio. É vinculado às condições de gestão.

Atualmente, nem todos os incentivos estão implementados. No entanto, a partir do banco de dados disponibilizado pelo Ministério da Saúde, pode-se perceber que os incentivos do Programa de Agentes de Saúde (PCCS) e do Programa de Saúde da Família (PSF) vêm sendo implementados com uma lógica redistributiva. Tomando como indicador de condições de saúde o coeficiente de mortalidade infantil, a tabela 3 mostra que a região Nordeste, com os piores coeficientes, recebeu os maiores incentivos, tanto em valores absolutos, como em aumento percentual do Piso de Atenção Básica - PAB fixo. Vale lembrar que o limite máximo de acréscimo do PAB (80\% para o PSF e $30 \%$ para o PCCS) ainda está longe de ser atingido.

A divisão por níveis de gerência, condicionados ao cumprimento de requisitos, também permanece como obstáculo à eqüidade. No entanto, houve um incremento significativo no número de municípios habilitados. Segundo dados do Ministério da Saúde (2000), a única região a apresentar um percentual de população residente em municípios não habilitados menor que $80 \%$ é a Sudeste. Todas as demais possuem mais de $90 \%$ de sua população residente em municípios habilitados ao repasse de verbas federais e classificados segundo um dos tipos de gestão.

É importante chamar a atenção, no entanto, para o pequeno percentual de municípios incluídos na Gestão Plena do Sistema de Saúde. No Brasil, são 88\% em Gestão Plena da Atenção Básica (GPAB) e 9\% em Gestão Plena do Sistema Municipal (GPS). Em relação à última, este índice varia de zero nos estados do Amapá e Sergipe até 45\% dos municípios no estado do Espírito Santo. Vale lembrar que, 
Tabela 3

Repasse de verbas federais para atenção básica dos municípios, segundo estados e regiões do Brasil, 1999.

\begin{tabular}{|c|c|c|c|c|}
\hline \multirow[t]{2}{*}{ Estado/Região } & \multirow[t]{2}{*}{ PAB fixo* } & \multicolumn{2}{|c|}{$\mathrm{PSF}+\mathrm{PCCS}^{\star *}$} & \multirow{2}{*}{$\begin{array}{l}\text { Coeficiente de } \\
\text { mortalidade } \\
\text { infantil } 1997\end{array}$} \\
\hline & & valor & $\begin{array}{l}\% \text { de aumento } \\
\text { do PAB fixo }\end{array}$ & \\
\hline Amazonas & $22.574 .850,10$ & $3.917 .488,85$ & 17,35 & 35,37 \\
\hline Tocantins & $12.031 .160,70$ & $6.865 .123,15$ & 57,06 & 33,74 \\
\hline Amapá & $4.126 .668,25$ & $1.207 .651,22$ & 29,26 & 32,12 \\
\hline Acre & $4.397 .306,53$ & $1.446 .402,73$ & 32,89 & 45,25 \\
\hline Rondônia & $13.592 .380,24$ & $4.359 .388,03$ & 32,07 & 35,02 \\
\hline Pará & $56.621 .196,21$ & $14.954 .385,65$ & 26,41 & 36,22 \\
\hline Roraima & $2.412 .997,86$ & $415.086,04$ & 17,20 & 38,85 \\
\hline Norte & $115.756 .559,89$ & $33.165 .525,67$ & 28,65 & 36 \\
\hline Paraíba & $34.618 .955,68$ & $9.307 .754,79$ & 26,89 & 65,21 \\
\hline Pernambuco & $89.836 .795,29$ & $24.058 .888,35$ & 26,78 & 62,74 \\
\hline Rio Grande do Norte & $26.774 .484,98$ & $8.147 .703,40$ & 30,43 & 60,37 \\
\hline Bahia & $129.246 .880,30$ & $29.619 .899,08$ & 22,92 & 51 \\
\hline Piauí & $32.175 .299,09$ & $9.897 .296,54$ & 30,76 & 51,94 \\
\hline Sergipe & $20.592 .700,79$ & $5.710 .145,20$ & 27,73 & 54,09 \\
\hline Alagoas & $30.305 .429,67$ & $11.843 .936,47$ & 39,08 & 74,07 \\
\hline Ceará & $76.227 .919,41$ & $34.084 .430,57$ & 44,71 & 56,26 \\
\hline Maranhão & $57.715 .974,17$ & $12.890 .516,46$ & 22,33 & 60,94 \\
\hline Nordeste & $497.494 .439,38$ & $145.560 .570,86$ & 29,26 & 58,31 \\
\hline Minas Gerais & $193.399 .656,92$ & $28.956 .876,22$ & 14,97 & 28,84 \\
\hline Espírito Santo & $28.500 .463,04$ & $2.456 .418,29$ & 8,62 & 28,45 \\
\hline Rio de Janeiro & $140.138 .031,95$ & $3.963 .011,09$ & 2,83 & 25,6 \\
\hline São Paulo & $340.760 .487,05$ & $8.861 .569,89$ & 2,60 & 24,63 \\
\hline Sudeste & $702.798 .638,96$ & $44.237 .875,49$ & 6,29 & 26,08 \\
\hline Santa Catarina & $51.502 .298,02$ & $5.512 .588,02$ & 10,70 & 23,37 \\
\hline Paraná & $110.324 .116,70$ & $12.953 .893,43$ & 11,74 & 28,47 \\
\hline Rio Grande do Sul & $96.986 .006,72$ & $6.908 .118,05$ & 7,12 & 19,66 \\
\hline Sul & $258.812 .421,44$ & $25.374 .599,50$ & 9,80 & 24,03 \\
\hline Distrito Federal & 19272957,16 & $2.836 .641,33$ & 14,72 & 24,84 \\
\hline Mato Grosso do Sul & $19.958 .332,87$ & $3.392 .563,44$ & 17,00 & 26,98 \\
\hline Goiás & $49.877 .551,74$ & $7.468 .356,11$ & 14,97 & 27,13 \\
\hline Mato Grosso & $27.086 .947,92$ & $4.098 .739,79$ & 15,13 & 28,57 \\
\hline Centro-Oeste & 116195789,7 & $17.796 .300,67$ & 15,32 & 27,05 \\
\hline Brasil & $1.691 .057 .849,36$ & $266.134 .872,19$ & 15,74 & 37,39 \\
\hline
\end{tabular}

* PAB: Piso Assistencial Básico.

** PSF: Programa de Saúde da Família; PCCS: Programa de Agentes Comunitários de Saúde.

Fontes: colunas 1, 2 e 3 - Ministério da Saúde, 2000a; coluna 4- Ministério da Saúde, 2000b.

antes da implantação da NOB 96, era alto o grau de diferenciação existente entre municípios, com um percentual significativo de nãohabilitados ou incluídos na Gestão Incipiente ou Parcial. Esse desnível dificilmente foi anulado com o re-enquadramento promovido pela NOB 96. Assim, embora a grande maioria esteja habilitada e enquadrada na GPAB, as condições reais de gestão devem variar bastante.

A PPI - Programação Pactuada Integrada, realizada nas Comissões Intergestores, é o grande instrumento de promoção de eqüidade assumido pela NOB. 
O item 4, sobre sistema de saúde municipal, traz textualmente:

As instâncias básicas para a viabilização dos propósitos integradores e harmonizadores dos diferentes níveis do Sistema Único de Saúde, são os fóruns de negociação, integrados pelos gestores municipal, estadual e federal - a Comissão Intergestores Tripartite (CIT) - e pelos gestores estadual e municipal - a Comissão Intergestores Bipartite (CIB). Por meio dessas instâncias e dos Conselhos de Saúde, são viabilizados os princípios de unidade e de eqüidade (grifo meu).

O poder público estadual tem um papel de destaque, sendo responsável por harmonizar, integrar e modernizar os sistemas municipais, com eqüidade: as tarefas de harmonização, de integração e de modernização dos sistemas municipais, realizadas com a devida eqüidade (admitindo o princípio da discriminação positiva, no sentido da busca da justiça, quando do exercício do papel redistributivo), competem, portanto, por especial, ao poder público estadual. Ao Federal, incumbe promovê-las entre as Unidades da Federação (grifo meu).

A engenharia complexa implementada pela NOB 96 tem o ambicioso objetivo de promover a eqüidade, com qualidade e racionalidade nos gastos: a composição dos sistemas municipais e a ratificação das programações pactuadas nos Conselhos de saúde respectivos, permitem a construção de redes regionais que, certamente ampliam o acesso, com qualidade e menor custo. Essa dinâmica contribui para que seja evitado um processo acumulativo injusto por parte de alguns municipios (quer por maior disponibilidade tecnológica, quer por mais recursos financeiros ou de informação), com a conseqüente espoliação crescente de outros.

E mais adiante: a ameaça da ocorrência de gastos exagerados, em decorrência de um processo de incorporação tecnológica acrítico e desregulado, é um risco que pode ser minimizado pela radicalização na reorganização SUS: um sistema regido pelo interesse público e balizado, por um lado, pela exigência da universalização e integralidade com eqüidade e, por outro, pela própria limitação de recursos, que deve ser programaticamente respeitada (Ministério da Saúde, 1996).

No entanto, o principal instrumento adotado pela NOB - a PPI - pode ser também o seu maior problema. Praticamente todos os recursos são definidos e distribuídos de acordo com o determinado pelas Comissões Intergestores.
Pode-se citar como exemplo: o elenco de procedimentos e o valor per capita do PAB, os critérios para alocação dos incentivos à obtenção de impactos positivos sobre condições de vida e saúde e o valor do Teto Financeiro de Epidemiologia e Controle de Doenças. Uma relação de oposição política, entre determinado município e o estado, pode influenciar nos rumos da PPI prejudicando o município. Vale lembrar também, que as Comissões Intergestores são órgãos representativos, não contando, portanto, com a participação direta de todos os gestores interessados na alocação de verbas. Neste contexto, a inexistência de um valor mínimo a ser adotado ou de um elenco mínimo de critérios que sejam preestabelecidos deixa os municípios extremamente vulneráveis aos conflitos políticos e sujeitos a grandes flutuações no repasse de verbas, o que prejudica o planejamento e programação das ações municipais.

Muito embora o avanço na legislação seja inegável, alguns aspectos adicionais da realidade, além daqueles já apontados em relação às normas vigentes - como defasagem nos valores das tabelas de procedimentos e dificuldade de fiscalização para evitar fraudes -, acabam por dificultar que o setor público de saúde escape do habitual rótulo de ineficiência que, nos últimos tempos, foi apontado tanto por aqueles que defendem a consolidação do SUS, nos moldes definidos na Constituição de 1988, como pelos defensores do projeto de reforma sanitária em discussão na arena nacional, que propõe, em última análise, a transferência para o setor privado, da tarefa de produzir serviços.

Em relação a este último ponto, vale a pena contextualizar o debate sobre a reforma do sistema de saúde brasileiro, a fim de identificar as possíveis conseqüências sobre a eqüidade em saúde.

\section{Reforma x Eqüidade}

Para Almeida (1996a), a agenda atual de mudanças faz parte de uma fase no desenvolvimento dos sistemas de saúde do mundo ocidental, iniciada nos anos 70 e 80 , a partir da crise econômica dos países industrializados e exacerbada por renovados ataques ao welfare state keynesiano e por uma inflação sempre crescente dos custos com assistência médica.

As justificativas de reforma do sistema de saúde tiveram, essencialmente, o mesmo con- 
teúdo da crítica ao welfare state, que partia das seguintes premissas: seus ganhos em busca de eqüidade teriam sido menores do que as perdas de eficiência produzidas pela intervenção estatal; o governo, em relação ao setor privado, seria ineficiente, tendo, inclusive, estimulado disfunções ao tentar corrigir falhas de mercado, e o aumento da intervenção do Estado na área social teria provocado desmotivação e dependência dos indivíduos, já que a provisão pública baseia-se em “julgamentos morais de necessidades" e não em demandas reais (Almeida, 1996).

A crise econômica trouxe também para o centro do debate, em praticamente todos os países industrializados, os altos custos da assistência médica, ocasionados pelo envelhecimento da população e o desenvolvimento das tecnologias médicas. No primeiro caso, devido ao aumento da ocorrência das doenças crônico-degenerativas e ao incremento da demanda por serviços de saúde. No segundo caso, em decorrência do rápido avanço das tecnologias médicas, muitas vezes com efeito cumulativo, já que nem sempre dispensam o uso das tecnologias tradicionais. A preocupação com a otimização da utilização dos recursos em saúde levou vários países a adotarem, desde a década de 1970, medidas para conter os custos de seus sistemas. Abel-Smith e Mossialos (1994) apontam para o impacto destas medidas: o crescimento dos gastos setoriais em relação ao Produto Interno Bruto, na década de 1980, foi menor do que na década de 1970, na maioria dos países desenvolvidos. O ritmo de crescimento dos gastos com saúde, nestes países, vinha sendo sistematicamente mais pronunciado do que o aumento das riquezas nacionais.

A agenda de reformas ocorrida inicialmente nos países centrais, expandiu-se para a periferia a partir dos anos 90 . No entanto, diferente do que ocorreu na Europa nos anos 80, onde o objetivo dos cortes e ajustes era de manter os gastos sociais em níveis suportáveis, na América Latina e Caribe o gasto social foi um instrumento de ajuste fiscal, enquanto sua função compensatória foi secundarizada. O diagnóstico formulado nos países centrais foi usado para questionar se os modelos de sistema de saúde latino-americanos (segundo este diagnóstico: caros, inflacionários, ineficientes e viabilizados através de forte investimento público) seriam pertinentes e/ou adequados para enfrentar o extenso quadro de carên- cias e iniqüidades existente na região. Os princípios da universalidade e da eqüidade nos cuidados de saúde passaram a ser claramente questionados nos locais onde já existiam e, onde ainda eram uma aspiração, passou-se a defender a impossibilidade de alcançá-los.

As agências internacionais tiveram papel de destaque na implementação das reformas nos países periféricos. Uma leitura mais aprofundada sobre este assunto pode ser encontrada em Costa (1996). No final dos anos 80 e início dos anos 90, dois documentos, divulgados pelo Banco Mundial, formalizaram o diagnóstico da situação latino-americana e propuseram uma agenda para a região, pautada na afirmação de que, na área social, os recursos eram escassos, as necessidades crescentes e o leque de alternativas restrito. A opção de política de saúde, adotada pelo banco foi: defender a diminuição do papel do Estado e o fortalecimento do mercado para a produção de bens e serviços; estimular novas parcerias com setores não-governamentais e propor mudanças no financiamento setorial segundo as condicionalidades impostas pelos ajustes econômicos. A política compensatória recomendada, trabalhava com uma concepção sintética do social, baseada em princípios de seletividade territorial e focalização dos gastos públicos, através da implementação de pacotes básicos de intervenções em saúde pública e assistência médica comprovadamente custo-efetivas para os mais pobres.

A experiência tem demonstrado que essa política compensatória não produz os mesmos resultados de uma discriminação positiva dos menos favorecidos, adotada para produzir uma eqüidade de resultados, em especial devido aos diferentes cenários existentes nos países centrais e periféricos. Nos primeiros, as reformas nos sistemas de saúde se dão, em geral, numa conjuntura onde os direitos de cidadania encontram-se consolidados e a qualidade mínima na assistência garantida, independente da parcela de serviços de saúde que fica sob a responsabilidade do Estado. Já nos países periféricos a situação é diferente. Tamez chama a atenção para as mudanças ocorridas na maioria dos países da América Latina, que implicaram cortes nos gastos públicos, política de ajuste e aumento da participação do setor privado em áreas que haviam sido quase exclusividade do setor público: $d a-$ do que, na América Latina os processos de privatização dos serviços de saúde têm se dado em 
condições de uma crescente desigualdade social e frente a uma cidadania imatura, estes processos apontam para uma iniquidade também crescente (Tamez, 1995).

As idéias neoliberais subjacentes às propostas das agências internacionais nortearam também as proposições de reforma em pauta no Brasil. De acordo com o Ministério da Reforma Administrativa do Estado (Brasil, 1995) reformar o Estado significa transferir para o setor privado as atividades que podem ser controladas pelo mercado e publicizar, ou descentralizar para o setor público não-estatal, serviços que não envolvem o exercício do poder de Estado, mas devem ser subsidiados por ele, como saúde, educação, cultura e pesquisa científica. A reforma preconizada deve ser levada a cabo a partir da lógica da administração pública gerencial, inspirada na administração de empresas, onde a eficiência da administração pública - a necessidade de reduzir custos e aumentar a qualidade dos serviços, tendo o cidadão como beneficiário - é essencial.

A partir dessa lógica o sistema público produtor de serviços é posto a competir com o setor privado lucrativo na captação de recursos - o que, como já foi visto, vem ocorrendo desde as normatizações do início da década - e na busca de modelos mais "eficientes" de prestação de serviços. Além das conseqüências já apontadas no texto, sob essa ótica, o conceito de eqüidade fica reduzido à cobertura dos serviços de assistência médica. O modelo busca não a solução das necessidades de saúde mas apenas atender às necessidades da demanda dos serviços assistenciais, o que é diferente. Isto significa um distanciamento radical na abordagem da eqüidade presente na Constituição de 1988 e na lei 8.080. Ademais, a flexibilização dos contratos públicos e a transformação dos serviços em empresas de direito privado, como lembra Almeida (1996b), podem possibilitar maior agilidade gerencial em nível executivo, porém, podem também acarretar a perda dos instrumentos de controle estatal que foram mais efetivos para a contenção de custos, como atestam as experiências européias.

Para dar contornos mais nítidos ao cenário onde se trava o debate sobre a reforma do sistema de saúde brasileiro e para completar o panorama sobre a questão da eqüidade na legislação, é interessante mencionar também o papel ocupado pelo setor privado de prestação de serviços de saúde.

\section{O setor privado de saúde no Brasil}

Historicamente, no final da década de 1960 e início da década seguinte, foram criadas as condições propícias para o surgimento do setor privado no Brasil, tanto do segmento que se tornou hegemônico na década de 1970 - o contratado e conveniado - como para o setor privado puro ou autônomo, da medicina supletiva.

Entre os principais acontecimentos que marcaram o cenário daquela época estão:

- a criação do Instituto Nacional da Previdência Social, em 1966, que trouxe a uniformização dos benefícios oferecidos aos trabalhadores e ampliação da cobertura previdenciária; - a instituição do Fundo de Apoio ao Desenvolvimento Social (FAS), em 1974, destinado a financiar o investimento fixo de setores sociais;

- a implantação do Plano de Pronta Ação (PPA), também em 1974, que, entre outras coisas, estabeleceu normas para convênios com empresas para prestação de assistência médica e reorganizou as relações da Previdência Social, através da definição de formas de pagamento distintas para diferentes prestadores: contratos e credenciamentos por serviços prestados e convênios por subsídio fixo.

Mendes (1993) ressalta que a ação combinada do PPA e do FAS representou um mecanismo de alavancagem do setor privado de serviços ligados ao sistema público através de contratos e convênios; o primeiro garantindo a demanda e o segundo garantindo uma expansão física adicional. Este subsistema tornouse hegemônico na década de 1970, apresentando como características o capital fixo subsidiado, a reserva de mercado e, por conseqüência, baixíssimo risco empresarial e nenhuma competitividade.

Foi também a partir do PPA que foram criadas as condições para o crescimento de uma nova modalidade assistencial que surgira no final da década de 1970 - a medicina de grupo - viabilizada a partir do convênio-empresa. Nesta modalidade, a empresa responsabilizava-se direta ou indiretamente pela oferta de atenção médica a seus empregados, recebendo em troca um subsídio da previdência. Através do contrato homologado, as empresas podiam optar entre oferecer assistência médica pública ou privada subsidiada. No caso da segunda opção, uma empresa de assistência médica era contratada. As empresas contra- 
tantes recebiam, como subsídio do governo, um percentual do salário mínimo por trabalhador. Esta modalidade destinava-se a uma clientela específica, atingindo um operariado mais qualificado e com melhor padrão organizativo.

O sistema de atenção médica supletiva cresceu a passos largos durante a década de 1980, de tal modo que, em 1989 , cobria $22 \%$ da população total do país. Somente no período de 1987-1989 foram incorporados 7.200.000 usuários. Atualmente, são cerca de 42 milhões que correspondem a $26,8 \%$ da população total (Melo, 1998). Hoje, o sistema está conformado por quatro modalidades assistenciais principais: a medicina de grupo, as cooperativas médicas, os planos próprios das Empresas e o seguro-saúde. Cada uma dessas modalidades - cujas características gerais estão descritas em Almeida (1997) e Mendes (1993) - apresenta racionalidades de estruturação, clientelas e formas de financiamento diversas.

Segundo a Constituição e Leis Orgânicas, o setor privado deveria ocupar um papel complementar ao SUS que, por sua vez, garantiria um acesso universal e igualitário a toda a população. No entanto, alguns autores têm apontado para o processo de "universalização excludente" que acompanhou o desenvolvimento do sistema público de saúde brasileiro. Concomitante à ampliação do acesso para todos os cidadãos brasileiros, foi ocorrendo uma diminuição na qualidade dos serviços prestados, o que levou uma parcela cada vez maior da população a pagar pela assistência médica fornecida pelo setor privado autônomo, entendido como não-credenciado ou conveniado com o SUS (a este respeito ver Faveret \& Oliveira, 1989).

Caso os preceitos constitucionais fossem cumpridos, o setor privado poderia funcionar apenas como subsistema alternativo para camadas de maior poder de compra, sem comprometer a eqüidade. Contudo, isso não ocorre, dado o extremo grau de incentivo ao consumo desses serviços privados, o que, para autores como Mendes (1993), chega a colocar em dúvida o seu caráter liberal em termos econômicos. Seu argumento baseia-se na constatação de que o sistema privado alimenta-se das deduções do imposto de renda das pessoas físicas que, até 1986 e depois a partir de 1990, são integrais em termos do imposto a pagar. Em relação às pessoas jurídicas, a legislação em vigor considera os serviços de saúde como custos operacionais das empresas, permitindo repassá-los aos preços dos produtos. Como conseqüência, a atenção médica supletiva - que é ofertada a grupos privilegiados - é financiada, em última instância, pelo conjunto da população brasileira, o que aumenta o grau de regressividade do sistema de saúde.

Quanto à legislação, a primeira tentativa de regulamentação de planos privados de saúde ocorreu em 1966, com o decreto lei 73, sobre seguros privados. Essa tentativa, no entanto, não teve êxito porque o decreto 60.459/67 (regulamento do decreto anterior) não estabeleceu qualquer norma de fiscalização dos planos (Ramos, 1997). Apesar de várias tentativas ocorridas desde então, somente mais de 30 anos depois foram regimentadas, na lei 9.656, de 3 de junho de 1998, as normas que regulam a oferta dos planos de saúde pelo setor privado.

O termo eqüidade não aparece na lei 9.656. O seu espírito é regulamentar a oferta de serviços, numa relação de mercado entre vendedores e consumidores, buscando diminuir a possibilidade dos usuários serem lesados. São 36 artigos que versam sobre a operação de planos ou seguros de saúde, instituindo normas de funcionamento e fiscalização, definindo os serviços que obrigatoriamente devem ser oferecidos, limitando exclusões, carências e definindo regras para aumentos de preços. Em que pese o avanço que significa para os usuários de planos de saúde, não se pode considerá-la como parte do arcabouço jurídico legal que fundamenta um sistema de saúde comprometido com o princípio da eqüidade.

\section{Conclusões}

O quadro sanitário brasileiro mostra a existência de profundas desigualdades entre regiões e grupos sociais que, longe de expressar diferenças aceitáveis nos níveis de saúde, são plenamente evitáveis e portanto injustas. As políticas sociais tiveram historicamente um caráter regressivo, concentrando recursos nas regiões mais desenvolvidas em detrimento daquelas onde são piores as condições de vida. Seu papel, na realidade, foi inverso àquele apontado como produtor de eqüidade, que seria o de reduzir ou eliminar fatores evitáveis e injustos e oferecer serviços de saúde capazes de atender ao "superávit" de necessidades criadas pelas iniqüidades sociais. Este quadro, re- 
flexo do profundo abismo social que separa os pobres dos privilegiados, representa um enorme desafio a ser enfrentado por políticas sociais responsáveis.

Quanto à concepção de eqüidade presente na legislação brasileira, pode-se concluir que os mecanismos instituídos pelas Normas Operacionais Básicas de 1991 e 1993 ficaram longe dos critérios previstos no artigo $35 \mathrm{da}$ lei 8.080. Foram regressivos quando não respeitaram as diferenças no perfil epidemiológico da clientela do setor público e privado, ou das diferentes regiões do país e quando contribuíram para as iniqüidades regionais.

A NOB 96 por sua vez, representou um avanço em alguns aspectos do repasse de verbas para os municípios. A desconsideração das diferenças no perfil epidemiológico das clientelas pública e privada continua um obstáculo. No entanto, o repasse de verbas através de incentivos foi ampliado, possibilitando um aumento para as áreas com maiores problemas sanitários. Como questões a serem enfrentadas, aponta-se a própria complexidade da NOB 96 e o peso excessivo das negociações políticas, realizadas no interior das Comissões Intergestores, na definição de valores e critérios de repasses. Vale registrar que essa Norma Operacional sofreu algumas mudanças após a sua promulgação, encontrando-se ainda em fase de implementação.

Quanto à assistência prestada pelo setor privado, a regulamentação existente não envolve preocupação alguma com o princípio da eqüidade. Ademais, a atenção médica supletiva é propagandeada como um conjunto de modalidades assistenciais de custo zero para o Estado. Na realidade, o subsídio fornecido pelo governo aos usuários de serviços privados, funciona como expressão da gradação existente nos direitos de cidadania: para a grande parcela da população, cabe a assistência do SUS, com os conhecidos problemas de qualidade, e para uma pequena parcela, além do acesso ao SUS, cabe a assistência, teoricamente de melhor qualidade, obtida no setor privado. Em ambos os casos, os custos recaem sobre o conjunto da população.

Em relação às propostas de reforma do sistema de saúde, vale chamar a atenção para as conclusões de Almeida (1996b), que considera que a propriedade estatal dos serviços de saúde ou o tamanho do setor público não são, em si, variáveis especialmente críticas. A capacidade ou habilidade do governo de regular diretamente as diversas partes do setor saúde - com seus diferentes fatores de produção - é que é crítica, tanto para o planejamento quanto para a eficiência e a efetividade na distribuição da assistência médica, com maior cobertura e a um custo determinado. Esta tarefa, supõe, sem dúvida, a (re)afirmação da responsabilidade estatal pela adequada assistência à saúde dos cidadãos e das populações, seja essa assistência prestada por serviços públicos ou privados.

A essas observações, cabe acrescentar que compete ao setor público de saúde, e não ao privado, a tarefa de incorporar os princípios da eqüidade e da solidariedade às políticas sociais desenvolvidas, que precisam cumprir o duplo papel de atenuar as iniqüidades sociais, atuando sobre os fatores que determinam os diferenciais injustos e evitáveis em saúde, e prover toda a população de atenção e serviços que atendam às necessidades de saúde, respeitando as particularidades de cada grupo social, com o mesmo nível de qualidade. Apenas desta forma estará sendo desenhado um sistema de saúde equânime.

A luta pela reforma sanitária levada a cabo nos anos 80 imprimiu à Constituição e suas Leis Complementares uma concepção avançada de eqüidade. A Norma Operacional em vigor, embora ainda distante de concretizar os ditames constitucionais, ou de resolver os problemas de qualidade de todo o sistema, apresenta avanços importantes nesta direção. Por outro lado, a concretização do projeto de "reforma da reforma", nos moldes apresentados, implicará um afastamento ainda mais radical das conquistas obtidas no plano jurídico-legal. 


\section{Referências bibliográficas}

Abel-Smith B \& Mossialos E 1994. Cost containment and health care reform: a study of the European Union. Health Policy, 28:89-132.

Almeida C 1996a. Os modelos de reforma sanitária dos anos 80: uma análise crítica. Saúde e Sociedade, 5(1): 3-46.

Almeida C 1996b. Novos modelos de atenção à saúde. Bases conceituais e experiências de mudança. In Costa NR \& Ribeiro JM (org.). Política de saúde e inovação institucional. Uma agenda para os anos 90 . Secretaria de Desenvolvimento Educacional, ENSP Rio de Janeiro.

Almeida C 1997. A assistência médica suplementar no Brasil: panorama atual e tendências. Texto produzido por solicitação do IPEA/PNUD, como parte dos estudos que subsidiaram a elaboração do relatório IDH Brasil 1997. (Mimeo).

Brasil 1995. Plano diretor da reforma do aparelho do Estado. Presidência da República, Câmara da Reforma do Estado, Ministério da Administração Federal e Reforma do Estado, Brasília.

Costa NR 1996. O Banco Mundial e a política social nos anos 90. A agenda para a reforma do setor saúde no Brasil. In Costa NR \& Ribeiro JM (org.). Politica de saúde e inovação institucional. Uma agenda para os anos 90. Secretaria de Desenvolvimento Educacional, ENSP, Rio de Janeiro.

COSEMS RJ 1997. Manual do gestor SUS. Editora Lidador, Rio de Janeiro.

Faveret Filho P \& Oliveira PJ 1989. A universalização excludente - reflexões sobre as tendências do sistema da Saúde. UFRJ/IEI, Rio de Janeiro.

Giovanella L et al. 1996. Eqüidade em Saúde no Brasil. Saúde em Debate, 49-50:13-22, dez/95-mar/96.

IPEA 1996. Relatório sobre o desenvolvimento humano no Brasil 1996. Publicado para o Programa das Nações Unidas para o Desenvolvimento (PNUD), Brasília.

Le Grand DJ 1988. Equidad, salud y atención sanitaria. In Salud y equidad: VIII Jornadas de Economia de la Salud. Espanha.

Melo MA 1998. Relatório IDH - parte 3. Trabalho desenvolvido no âmbito do Projeto Bra/97/007 - IPEA/ PNUD, como parte integrante do Relatório sobre Desenvolvimento Humano - Brasil. (Mimeo).
Mendes EV 1993. As políticas de saúde no Brasil dos anos 80. In Mendes EV (org.). Distrito sanitário: o processo social de mudança das práticas sanitárias do Sistema Único de Saúde. Hucitec-Abrasco, São PauloRio de Janeiro.

Ministério da Saúde 1993. Norma Operacional BásicaSUS 01/1993. Portaria MS no 545, de 20 de maio de 1993, anexo único.

Ministério da Saúde 1996. Norma Operacional Básica SUS 01/1996. Portaria 2.203 de 5 de novembro de 1996.

Ministério da Saúde 1997a. Indicadores socioeconômicos. Informações em Saúde. (Mimeo, obtido via Internet, em abril).

Ministério da Saúde 1997b. Indicadores de recursos, acesso e cobertura. Informações em Saúde. (Mimeo, obtido via Internet, em abril).

Ministério da Saúde 2000a. Transferências a municípios. Informações em Saúde. Recursos Financeiros. (Mimeo, obtido via Internet, em 17 de janeiro).

Ministério da Saúde 2000b. Indicadores de saúde. Mortalidade. Rede Interagencial de Informações para a Saúde/IDB 98 Brasil. (Mimeo, obtido via Internet, em 17 de janeiro).

Ministério da Saúde 2000c. Indicadores demográficos básicos. Rede Interagencial de Informações para a Saúde/IDB 98 Brasil. (Mimeo, obtido via Internet, em 17 de janeiro).

Musgrove P 1995. Cost-effectiveness and the socialization of health care. Health Policy, 32:111-123.

Porto SM 1994. Distribuição eqüitativa de recursos financeiros no setor saúde. O financiamento da Saúde no Brasil. Série Economia e Financiamento no 4. OPAS, Brasília.

Ramos SG 1997. O preço nos planos de saúde. Jornal do Brasil, seção opinião, p. 9, 4 de setembro.

Tamez S Bodek C \& Eibenschutz C 1995. Lo público y lo privado, las seguradoras y la atención médica en México. Cadernos de Saúde Pública 11(4):579-87.

Turner B 1986. Equality. Ellis Horwood Limited-Tavistock Publications, Londres-Nova York. 